\title{
Urinary Sodium Concentration Is an Independent Predictor of All-Cause and Cardiovascular Mortality in a Type 2 Diabetes Cohort Population
}

\section{Pierre-Jean Saulnier, ${ }^{1,2,3}$ Elise Gand, ${ }^{4}$ Stéphanie Ragot, ${ }^{1,2,3}$ Lise Bankir, ${ }^{5,6}$ Xavier Piguel, ${ }^{4}$ Frédéric Fumeron, ${ }^{5,6,7}$ Vincent Rigalleau, ${ }^{8}$ Jean-Michel Halimi, ${ }^{9,10}$ Richard Marechaud, Ronan Roussel, ${ }^{5,6,7,8}$ Samy Hadjadj, ${ }^{1,2,3,4,11}$ and SURDIAGENE Study group ${ }^{1,2,3,4}$}

${ }^{1}$ CHU de Poitiers, Centre d'Investigation Clinique, Poitiers, France

${ }^{2}$ Université de Poitiers, UFR Médecine Pharmacie, CIC1402, Poitiers, France

${ }^{3}$ Inserm, CIC1402, Poitiers, France

${ }^{4}$ CHU Poitiers, Pole DUNE, Poitiers, France

${ }^{5}$ Inserm, UMRS1138, Centre de Recherche des Cordeliers, Paris, France

${ }^{6}$ Université Paris 6 Pierre et Marie Curie, Centre de Recherche des Cordeliers, Paris, France

${ }^{7}$ Université Paris 7 Denis Diderot, UMRS1138, Centre de Recherche des Cordeliers, Paris, France

${ }^{8}$ CHU Bordeaux, Service d'Endocrinologie, Diabétologie, Maladies Métaboliques et Nutrition, Bordeaux, France

${ }^{9}$ CHU Tours, Service de Néphrologie, Tours, France

${ }^{10}$ Université de Tours, Faculté de Médecine, Tours, France

${ }^{11}$ Inserm, U1082, Poitiers, France

Correspondence should be addressed to Pierre-Jean Saulnier; pierrejean.saulnier@gmail.com

Received 12 June 2016; Revised 18 October 2016; Accepted 22 November 2016; Published 1 February 2017

Academic Editor: Raffaele Marfella

Copyright (C) 2017 Pierre-Jean Saulnier et al. This is an open access article distributed under the Creative Commons Attribution License, which permits unrestricted use, distribution, and reproduction in any medium, provided the original work is properly cited.

Objective. Sodium intake is associated with cardiovascular outcomes. However, no study has specifically reported an association between cardiovascular mortality and urinary sodium concentration $\left(\mathrm{U}_{\mathrm{Na}}\right)$. We examined the association of $\mathrm{U}_{\mathrm{Na}}$ with mortality in a cohort of type 2 diabetes (T2D) patients. Methods. Patients were followed for all-cause death and cardiovascular death. Baseline $\mathrm{U}_{\mathrm{Na}}$ was measured from second morning spot urinary sample. We used Cox proportional hazard models to identify independent predictors of mortality. Improvement in prediction of mortality by the addition of $\mathrm{U}_{\mathrm{Na}}$ to a model including known risk factors was assessed by the relative integrated discrimination improvement (rIDI) index. Results. Participants $(n=1,439)$ were followed for a median of 5.7 years, during which 254 cardiovascular deaths and 429 all-cause deaths were recorded. $\mathrm{U}_{\mathrm{Na}}$ independently predicted all-cause and cardiovascular mortality. An increase of one standard deviation of $U_{\mathrm{Na}}$ was associated with a decrease of $21 \%$ of all-cause mortality and $22 \%$ of cardiovascular mortality. $U_{\mathrm{Na}}$ improved all-cause and cardiovascular mortality prediction beyond identified risk factors ( $\mathrm{rIDI}=2.8 \%, P=0.04$ and $\mathrm{rIDI}=4.6 \%, P=0.02$, resp.). Conclusions. In T2D, $\mathrm{U}_{\mathrm{Na}}$ was an independent predictor of mortality (low concentration is associated with increased risk) and improved modestly its prediction in addition to traditional risk factors.

\section{Introduction}

Patients with diabetes mellitus, and particularly type 2 diabetes (T2D), represent a large and growing population at increased risk of cardiovascular events and mortality. Recent data have confirmed that patients with diabetes have approximately twice as high a risk of mortality and vascular diseases as individuals without diabetes [1]. Blood pressure has been 
recognized as a key contributor to increased cardiovascular mortality [2].

Recent large-scale data have shown that estimated sodium intake was positively related to blood pressure [3]. Interestingly, in the general population but also in high cardiovascular risk, epidemiological data suggest a J-shape curve relationship between sodium intake and cardiovascular outcomes [4]. In most of these studies, sodium intake was indirectly assessed from sodium urinary concentration. As hyperglycemia might lead to polyuria and then modify urinary solute concentrations, the relationship between sodium excretion and cardiovascular mortality needs to be specifically established in diabetes patients. One study on type 1 diabetes (T1D) [5] together with one work we recently reported in patients with T2D [6] suggested a nonlinear relationship between sodium excretion and allcause death. In addition, it has been reported that low measured 24-hour sodium excretion was associated with increased mortality in patients with T2D [7]. However, until now no study has examined the association of urinary sodium concentration $\left(\mathrm{U}_{\mathrm{Na}}\right)$ and mortality in T2D patients. The measurement of spot $\mathrm{U}_{\mathrm{Na}}$ is a simple method for epidemiological approach and can easily be used in clinical practice. For this reason, our aim was to assess the relationship between spot urine $U_{\mathrm{Na}}$ and mortality with an observational approach in a single center prospective cohort of T2D patients.

\section{Materials and Methods}

2.1. Study Protocols and Participants. The present analyses include the subjects recruited in the SURDIAGENE study, a French single center inception cohort of T2D patients regularly visiting the Diabetes Department at Poitiers University Hospital, France [8]. Patients were included from 2002 to 2012 and outcome update has been performed every 2 years since 2007. The Poitiers University Hospital Ethics Committee approved the design (CPP Ouest III). All participants in the study gave their informed written consent.

2.2. Definition of Clinical Outcomes. The primary outcome was the occurrence of all-cause death. Hospital records, interviews with general practitioners, and the French death registry were used by an independent adjudication committee to establish death and its cause. The secondary outcome was the occurrence of cardiovascular death, defined according to the International Classification of Diseases, Tenth Revision (ICD-10, codes I00-I99). Vital status of all study participants was confirmed through December 31, 2013.

2.3. Procedures. Blood samples and second morning urine samples were obtained in patients after an overnight fast. Seated blood pressure was measured twice at 3 min intervals using a semiautomated device (Dinamap1846, Critikon, Tampa, FL, USA) after $10 \mathrm{~min}$ of seated rest. Systolic blood pressure (SBP) and diastolic blood pressure (DBP) levels were then calculated from the mean of the 2 consecutive measures.
2.4. Laboratory Methods. Serum and urine creatinine and urinary albumin concentrations were measured by nephelometry on a Modular System P (Roche Diagnostics GmbH, Mannheim, Germany). Renal function was estimated by glomerular filtration rate (eGFR) using the Chronic Kidney Disease Epidemiology formula [9]. Glycated hemoglobin was determined using a high performance liquid chromatography method with a ADAMS A1C HA-8160 analyzer (Menarini, Florence, Italy). Urinary sodium and potassium concentrations $\left(U_{K}\right)$ were determined by indirect potentiometry. Estimated daily sodium intake was derived from $\mathrm{U}_{\mathrm{Na}}$ measured on spot urine according to Kawasaki et al.s [10] and to Tanaka et al.s formulas [11]. This approach has been shown to provide reliable information in large epidemiological studies [12]. The urine to plasma creatinine ratio $\left(\mathrm{U}: \mathrm{P}_{\text {creat }}\right)$ was calculated as an estimate of the overall urine concentration [13]. Glycosuria was semiquantitatively assessed using a urine dipstick Multistix 8SG (Siemens Healthcare Diagnostics Ltd, Camberley, UK). Plasma N-terminal of pro-brain natriuretic peptide (NT-proBNP) and copeptin concentrations (a surrogate for vasopressin) were measured in fasting plasmaEDTA samples, collected at baseline, and kept frozen at $-80^{\circ} \mathrm{C}$ at Poitiers Biological Resources Center (BB-0033-00068). Plasma concentrations of NT-proBNP were measured using an electrochemiluminescent immunoassay (Elecsys proBNP II assay, Roche Diagnostics GmbH, Mannheim, Germany). An automated immunofluorescent sandwich immunoassay was used (BRAHMS Copeptin US KRYPTOR CT-proAVP; Thermofisher Scientific, Hennigsdorf, Germany) for the copeptin measurement.

2.5. Statistical Analysis. Patient characteristics are expressed as means \pm standard deviation (SD) or medians (interquartile range) for skewed distributions. Groups were compared using the $\chi^{2}$ test for categorical variables or parametric (ANOVA) or nonparametric (Kruskal-Wallis) tests for continuous variables. Skewed variables were log-transformed in order to normalize their distribution. Associations between $\mathrm{U}_{\mathrm{Na}}$ and other variables were tested with Spearman's rank correlation test or linear regression analysis where estimates were standardized by calculating them for 1-SD increment of each continuous variable. To model the association between estimated sodium excretion and clinical outcomes, we used restricted cubic splines. Based on restricted cubic spline analysis for sodium excretion and cardiovascular death, we selected 5-6.99 g/day as the reference category because this was the range associated with the lowest risk. The time to event was plotted according to the tertiles of $\mathrm{U}_{\mathrm{Na}}$, $\mathrm{U}_{\mathrm{K}}$, and $\mathrm{U}: \mathrm{P}_{\text {creat }}$ with cumulative incidence curves, and comparison was made using the Log-rank test. We estimated the risk of outcome associated with $U_{N a}$ using a Cox proportional hazard model. The effect of interaction of some variables on the relationship between $U_{\mathrm{Na}}$ and survival was examined by adding a corresponding interaction term in the model. Hazard ratios (HR) were standardized by calculating them for 1-SD increment of each continuous variable. A univariate model and two multivariate models were considered. The first multivariate model (Model A) was adjusted for age, sex, $\mathrm{U}_{\mathrm{Na}}, \mathrm{U}_{\mathrm{K}}, \mathrm{U}: \mathrm{P}_{\text {creat }}$, and estimated 
$24 \mathrm{~h}$ Na excretion. Manual backward selection procedure was applied to identify the best fitted Cox proportional hazard model for independent variables in the prediction of allcause and cardiovascular mortality. Variables associated with $\mathrm{U}_{\mathrm{Na}}$ were all selected and then removed from the model when $P$ value $\geq 0.05$ until all the remaining variables were significant. Generalized $c$-statistics [14] were calculated for models that included or excluded $U_{\mathrm{Na}}$ to the best fitted model and comparisons between nested models were performed by likelihood ratios tests. The relative integrated discrimination improvement (rIDI) index was calculated to assess the improvement in 5.7-year mortality risk prediction for $\mathrm{U}_{\mathrm{Na}}$ in addition to covariates of the best fitted model [15]. The 5.7-year risk was selected as it corresponds to the median of follow-up.

Three sensitivity analyses were performed. Firstly, patients with previous severe CKD, defined as eGFR < $30 \mathrm{~mL} \cdot \mathrm{min}^{-1} \cdot 1.73 \mathrm{~m}^{-2}$ or history of renal replacement therapy at baseline, were omitted. Secondly, to test whether low $U_{\mathrm{Na}}$ or low SBP reflects chronic heart failure (CHF), we excluded patients with cardiovascular history (defined as prior myocardial infarction or stroke) at baseline. As we did not have information on CHF per se, history of cardiovascular disease was used as a surrogate for $\mathrm{CHF}$. Thirdly, we used the competing risk model to estimate the subdistribution HR for cardiovascular death, while accounting for the competing risk of noncardiovascular deaths according to Fine and Gray method [16]. $P$ values $<0.05$ were considered statistically significant. Statistical analyses were performed with SAS version 9.3 (SAS Institute, Cary, NC).

\section{Results}

3.1. Baseline Characteristics. The population studied included 1,439 patients with follow-up data. The mean value of $U_{\mathrm{Na}}$ was $89 \pm 41 \mathrm{mmol} / \mathrm{L}$. The mean value of 24 -hour $\mathrm{Na}$ excretion was $4.6 \pm 1.8 \mathrm{~g} /$ day. The clinical and biological characteristics of the patients are presented according to baseline $\mathrm{U}_{\mathrm{Na}}$ tertiles (Table 1). Interestingly, people in the low $\mathrm{U}_{\mathrm{Na}}$ tertile had a lower SBP and DBP compared to those in the intermediate or high $\mathrm{U}_{\mathrm{Na}}$ tertiles $(P=0.012$ and $P<0.001$, resp. $)$.

Urinary sodium concentration was associated with age, sex, history of cardiovascular disease, use of diuretics, use of insulin, eGFR, uACR, $\mathrm{U}_{\mathrm{K}}, \mathrm{U}: \mathrm{P}_{\text {creat }}$, estimated $24 \mathrm{~h} \mathrm{Na}$ excretion, NT-proBNP, and glycosuria (Table 2). Patients with glycosuria had significantly higher $\mathrm{U}_{\mathrm{Na}}$ compared to nonglycosuric patients $(92.2 \pm 39.0$ versus $86.7 \pm 42.0 \mathrm{mmol} / \mathrm{L}$; $P=0.016)$.

3.2. All-Cause Mortality during Follow-Up. The median follow-up was 5.7 years (interquartile range 3.1-8.8 years), during which time 429 all-cause deaths (incidence rate 51 per 1000 person-years [95\% CI, 46-55]) and 254 cardiovascular deaths occurred (incidence rate 30 per 1000 person-years [95\% CI, 26-33]). The causes of noncardiovascular death were adjudicated as follows: cancer $(n=58)$, infection $(n=41)$, and other causes $(n=76)$. When patients were classified according to the $\mathrm{U}_{\mathrm{Na}}$ tertile distribution, those in the low
$\mathrm{U}_{\mathrm{Na}}$ tertile had the highest cardiovascular mortality (Logrank $P<0.0001$ ) as illustrated in Figure 1(a). Interestingly, a similar relationship was found between all-cause mortality and $\mathrm{U}_{\mathrm{K}}$ (Figure $1(\mathrm{~b})$ ) and $\mathrm{U}: \mathrm{P}_{\text {creat }}$ (Figure $1(\mathrm{c})$ ), and even the relationship was graphically less gradual. Urinary sodium concentration, but not $\mathrm{U}: \mathrm{P}_{\text {creat }}$, was a predictor of all-cause death after adjustment for $\mathrm{U}_{\mathrm{K}}, \mathrm{U}: \mathrm{P}_{\text {creat }}$, and estimation of $24 \mathrm{~h}$ urinary sodium excretion (Table 3 ). Urinary sodium concentration remained an independent predictor of allcause death in the final best fitted model: age, gender, use of insulin, uACR, copeptin, and NT-proBNP (Table 4). After adjustments for covariates of this best fitted model all-cause mortality was $21 \%$ lower for every 1 -SD increase of $\mathrm{U}_{\mathrm{Na}}(P<$ 0.001). The addition of $U_{\mathrm{Na}}$ increased the $c$-statistic from 0.776 to 0.780 (difference in $c$-statistic $=0.004, P<0.001$; rIDI $=2.8 \%, P=0.04)$.

\subsection{Cardiovascular Mortality during Follow-Up. We found} a similar pattern and a significant relationship between cardiovascular mortality and tertiles of $\mathrm{U}_{\mathrm{Na}}$ (Figure 2(a)), $\mathrm{U}_{\mathrm{K}}\left(\right.$ Figure $2(\mathrm{~b})$ ), and $\mathrm{U}: \mathrm{P}_{\text {creat }}$ (Figure $2(\mathrm{c})$ ). Urinary sodium concentration, but not $\mathrm{U}: \mathrm{P}_{\text {creat }}$, was a also predictor of cardiovascular death after adjustment for $\mathrm{U}_{\mathrm{K}}, \mathrm{U}: \mathrm{P}_{\text {creat }}$, and estimation of $24 \mathrm{~h}$ urinary sodium excretion (Table 5).

In the best fitted model for cardiovascular death prediction (age, sex, BMI, use of insulin, uACR, $\mathrm{U}_{\mathrm{Na}}$, and NT-proBNP), $\mathrm{U}_{\mathrm{Na}}$ was also an independent risk factor for cardiovascular death. In this model, cardiovascular mortality was $24 \%$ lower for every $1-\mathrm{SD}$ increase of $\mathrm{U}_{\mathrm{Na}}(P<0.0001)$ as detailed in Table 6 .

The addition of $\mathrm{U}_{\mathrm{Na}}$ increased the $c$-statistic from 0.803 to 0.807 (difference in $c$-statistic $=0.004, P=0.0002$; rIDI $=$ $4.6 \%, P=0.02)$. There was no significant difference of allcause and cardiovascular death according to glycosuria (Logrank $P=0.80$ and 0.60 , resp.). We found no interaction of glycosuria, use of diuretics, or use of insulin with the association between urinary concentrations and either all-cause or cardiovascular death. 24-hour $\mathrm{Na}$ excretion considered as a 3-category variable (reference group $=5-5.99 \mathrm{~g} /$ day) was not significantly associated with all-cause or cardiovascular mortality; even graphical representation of the relationship evocated nonlinear J-shape relationship. Considering Tanaka's formulas instead of Kawasaki's for estimating 24hour $\mathrm{Na}$ excretion did not modify the results of the final Cox models.

Because severe CKD is an established independent risk factor for cardiovascular complications, we focused on a subset of patients with $\mathrm{eGFR} \geq 30 \mathrm{~mL} \cdot \mathrm{min}^{-1} \cdot 1.73 \mathrm{~m}^{-2}$ and no history of renal replacement therapy ( $n=1,035$ patients). In this subgroup, $\mathrm{U}_{\mathrm{Na}}$ was not correlated with $\mathrm{SBP}(r=0.04, P=$ $0.24)$. All-cause and cardiovascular deaths were registered in 229 (22\%) and 123 (12\%) patients, respectively. Results were unchanged with a clear graded protective effect of $U_{\mathrm{Na}}$ : allcause and cardiovascular mortality were $19 \%$ and $21 \%$ lower for every $1-\mathrm{SD} \mathrm{U}_{\mathrm{Na}}$ increase in the corresponding best fitted model; $P=0.005$ and $P=0.02$, respectively.

In the group of patients without any personal cardiovascular history at baseline ( $n=1,151$ patients), all-cause death and cardiovascular death were registered in 304 (26\%) 
TABLE 1: Baseline characteristics according to tertiles of urinary sodium concentration.

\begin{tabular}{|c|c|c|c|c|c|}
\hline & \multicolumn{5}{|c|}{ Tertiles of urinary sodium concentration } \\
\hline & $\begin{array}{c}\text { All } \\
(n=1,439)\end{array}$ & $\begin{array}{l}\text { Low } \\
<69 \mathrm{mmol} / \mathrm{L} \\
(n=479)\end{array}$ & $\begin{array}{c}\text { Intermediate } \\
69-103 \mathrm{mmol} / \mathrm{L} \\
(n=481)\end{array}$ & $\begin{array}{c}\text { High } \\
>103 \mathrm{mmol} / \mathrm{L} \\
(n=479)\end{array}$ & $P$ value \\
\hline \multicolumn{6}{|l|}{ Clinical variables } \\
\hline Age (year) & $65.3 \pm 10.7$ & $66.1 \pm 10.6$ & $65.6 \pm 10.5$ & $64.0 \pm 10.8$ & 0.008 \\
\hline Male, $n(\%)$ & $835(58 \%)$ & $252(53 \%)$ & $282(59 \%)$ & $301(63 \%)$ & 0.006 \\
\hline Body mass index $\left(\mathrm{kg} / \mathrm{m}^{2}\right)$ & $31.2 \pm 6.3$ & $31.2 \pm 6.4$ & $30.7 \pm 6.0$ & $31.9 \pm 6.3$ & 0.02 \\
\hline Active smoking, $n(\%)$ & $152(11 \%)$ & $48(10 \%)$ & $48(10 \%)$ & $56(12 \%)$ & 0.66 \\
\hline Diabetes duration (years) & $14.5 \pm 10.0$ & $15.9 \pm 10.1$ & $15.1 \pm 10.4$ & $12.5 \pm 9.3$ & $<0.001$ \\
\hline $\mathrm{HbA}_{1 \mathrm{c}}(\%)$ & $7.8 \pm 1.6$ & $7.7 \pm 1.7$ & $7.8 \pm 1.7$ & $7.7 \pm 1.5$ & 0.47 \\
\hline History of cardiovascular disease, $n(\%)$ & $276(19 \%)$ & $113(24 \%)$ & $87(18 \%)$ & $76(16 \%)$ & 0.005 \\
\hline Systolic blood pressure $(\mathrm{mmHg})$ & $132 \pm 18$ & $131 \pm 18$ & $134 \pm 18$ & $133 \pm 16$ & 0.03 \\
\hline Diastolic blood pressure (mmHg) & $72 \pm 11$ & $71 \pm 11$ & $73 \pm 10$ & $73 \pm 12$ & 0.002 \\
\hline \multicolumn{6}{|l|}{ Medications use } \\
\hline Any Diabetes therapy, $n(\%)$ & $1,378(96 \%)$ & $462(97 \%)$ & $457(95 \%)$ & $459(96 \%)$ & 0.62 \\
\hline Oral antidiabetic agent, $n(\%)$ & $910(63 \%)$ & $279(58 \%)$ & $294(61 \%)$ & $337(71 \%)$ & $<0.001$ \\
\hline Insulin, $n(\%)$ & $864(60 \%)$ & $322(67 \%)$ & $292(61 \%)$ & $250(52 \%)$ & $<0.001$ \\
\hline Any antihypertensive therapy, $n(\%)$ & $1189(83 \%)$ & $426(89 \%)$ & $394(82 \%)$ & $369(77 \%)$ & $<0.001$ \\
\hline Diuretics, $n(\%)$ & $655(46 \%)$ & $268(57 \%)$ & $210(44 \%)$ & $177(37 \%)$ & $<0.001$ \\
\hline RAAS blockers, $n(\%)$ & $900(63 \%)$ & $316(66 \%)$ & $301(63 \%)$ & $283(60 \%)$ & 0.05 \\
\hline Beta blockers, $n(\%)$ & $483(34 \%)$ & $185(39 \%)$ & $163(34 \%)$ & $135(28 \%)$ & 0.002 \\
\hline Calcium channel blockers, $n(\%)$ & $448(31 \%)$ & $162(34 \%)$ & $146(31 \%)$ & $140(29 \%)$ & 0.23 \\
\hline \multicolumn{6}{|l|}{ Renal parameters } \\
\hline eGFR $\left(\mathrm{ml} \cdot \mathrm{min}^{-1}\right.$ per $\left.1.73 \mathrm{~m}^{-2}\right)$ & $73 \pm 25$ & $65 \pm 27$ & $73 \pm 24$ & $81 \pm 19$ & $<0.001$ \\
\hline uACR (mg/g) & $3.0(12.9)$ & $4.1(18.2)$ & $3.5(15.1)$ & $2.4(7.6)$ & $<0.001$ \\
\hline $\begin{array}{l}\text { Diabetic nephropathy } \\
\text { (normo-/micro-/macroalbuminuric): } n \text { (\%) }\end{array}$ & $\begin{array}{c}528(43 \%) / 421 \\
(34 \%) / 293 \\
(24 \%)\end{array}$ & $\begin{array}{c}163(40 \%) / 119 \\
(29 \%) / 127(31 \%)\end{array}$ & $\begin{array}{c}173(41 \%) / 149 \\
(35 \%) / 100(24 \%)\end{array}$ & $\begin{array}{c}192(47 \%) / 153 \\
(37 \%) / 66(16 \%)\end{array}$ & $<0.001$ \\
\hline $\mathrm{U}_{\mathrm{Na}}(\mathrm{mmol} / \mathrm{L})$ & $89 \pm 41$ & $45 \pm 15$ & $85 \pm 10$ & $135 \pm 26$ & $<0.001$ \\
\hline $\mathrm{U}_{\mathrm{K}}(\mathrm{mmol} / \mathrm{L})$ & $52 \pm 25$ & $47 \pm 26$ & $51 \pm 24$ & $59 \pm 24$ & $<0.001$ \\
\hline $\mathrm{U}: \mathrm{P}_{\text {creat }}$ & $91(89)$ & $70(85)$ & $82(78)$ & $114(84)$ & $<0.001$ \\
\hline Estimated $24 \mathrm{~h} \mathrm{Na}$ excretion (g/day) & $4.6 \pm 1.8$ & $3.5 \pm 1.4$ & $4.9 \pm 1.5$ & $5.5 \pm 1.7$ & \\
\hline NT-proBNP $(\mathrm{pg} / \mathrm{mL})$ & $113(270)$ & $155(530)$ & $113(241)$ & $83(147)$ & \\
\hline Copeptin $(\mathrm{pmol} / \mathrm{L})$ & $6.7(8.0)$ & $6.7(10.7)$ & $6.2(7.2)$ & $7.3(6.7)$ & 0.07 \\
\hline Presence of glycosuria: $n(\%)$ & $494(34 \%)$ & $143(30 \%)$ & $170(35 \%)$ & $181(38 \%)$ & 0.03 \\
\hline
\end{tabular}

Quantitative variables are described by mean \pm SD or median (IQR).

History of cardiovascular disease $=$ history of stroke or myocardial infarction; RAAS blockers $=$ angiotensin receptor blockers and/or ACE inhibitors. eGFR, CKD EPI equation; $u A C R$, urinary albumin/creatinine ratio; $U_{N a}$, urinary sodium concentration; $U_{K}$, urinary potassium concentration; $U$ : $P_{\text {creat }}$, urinary to plasma creatinine concentration ratio; NT-proBNP, N-terminal pro-brain natriuretic peptide.

and 165 (14\%) patients, respectively. Results were similar as $\mathrm{U}_{\mathrm{Na}}$ remained significant predictor of mortality (all-cause mortality and cardiovascular mortality were $18 \%$ and $23 \%$ lower for every 1-SD increase of $\mathrm{U}_{\mathrm{Na}}$ in the corresponding best fitted model; $P=0.003$ and $P=0.005$, resp.). Accounting for the competing risk of noncardiovascular mortality in a Fine and Gray analysis (Table 6) did not modify results and $\mathrm{U}_{\mathrm{Na}}$ remained independently associated with a decrease in risk of cardiovascular death $(P=0.007)$.
Presence of glycosuria or use of diuretics/insulin did not interact with the association of $U_{\mathrm{Na}}$ and the risk of mortality, whatever its cause, in these subpopulations.

\section{Discussion}

The present study reveals a significant negative prognostic value of $U_{\mathrm{Na}}$ for all-cause and cardiovascular mortality in a prospective cohort of T2D patients. Even though they 

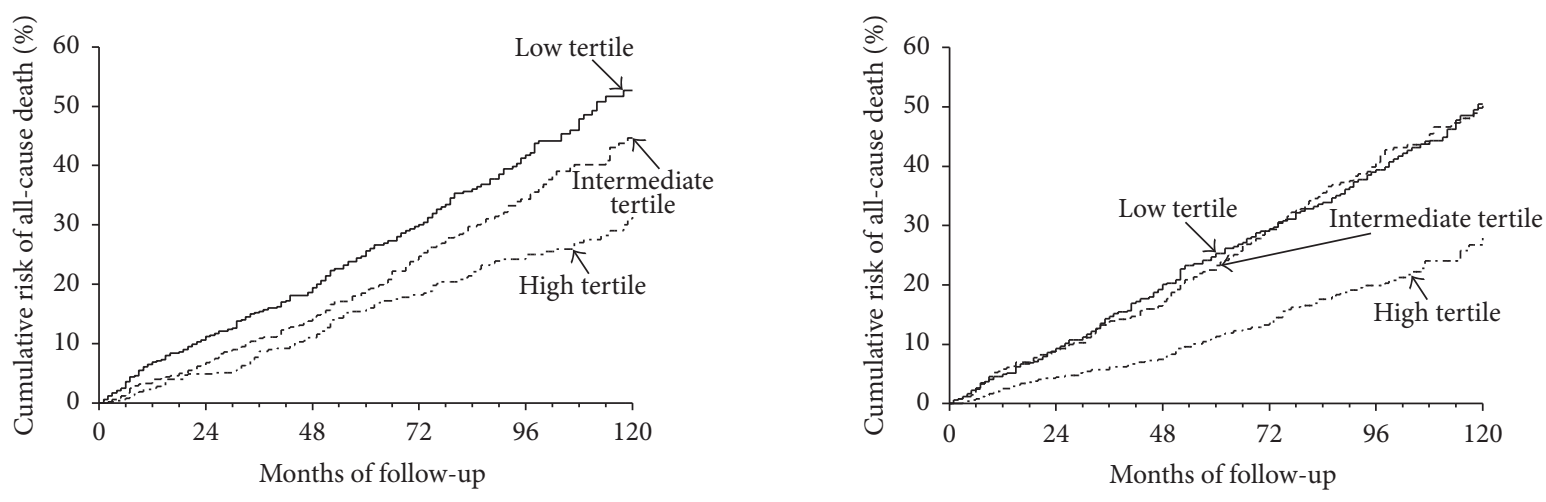

\begin{tabular}{lcccccc}
\hline $\begin{array}{l}\text { Number at } \\
\text { risk }\end{array}$ & & & & & & \\
\hline $\begin{array}{l}\text { Low } \mathrm{U}_{\mathrm{Na}} \\
\text { tertile }\end{array}$ & 479 & 426 & 333 & 255 & 192 & 61 \\
$\begin{array}{l}\text { Intermediate } \\
\mathrm{U}_{\mathrm{Na}} \text { tertile }\end{array}$ & 481 & 424 & 341 & 246 & 170 & 59 \\
$\begin{array}{l}\text { High } \mathrm{U}_{\mathrm{Na}} \\
\text { tertile }\end{array}$ & 479 & 399 & 291 & 195 & 124 & 40 \\
\hline
\end{tabular}

\begin{tabular}{lcccccc}
\hline $\begin{array}{l}\text { Number at } \\
\text { risk }\end{array}$ & & & & & & \\
\hline $\begin{array}{l}\text { Low } \mathrm{U}_{\mathrm{K}} \\
\text { tertile }\end{array}$ & 485 & 416 & 307 & 210 & 144 & 49 \\
$\begin{array}{l}\text { Intermediate } \\
\mathrm{U}_{\mathrm{K}} \text { tertile }\end{array}$ & 477 & 416 & 326 & 225 & 150 & 54 \\
$\begin{array}{l}\text { High } \mathrm{U}_{\mathrm{K}} \\
\text { tertile }\end{array}$ & 477 & 423 & 331 & 263 & 191 & 60 \\
\hline
\end{tabular}

(a)

(b)

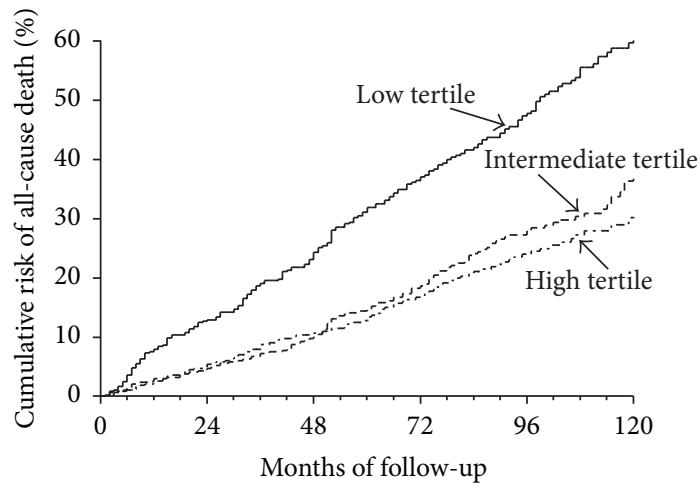

\begin{tabular}{lcccccc}
\hline $\begin{array}{l}\text { Number at } \\
\text { risk }\end{array}$ & & & & & & \\
\hline $\begin{array}{l}\text { Low U }: P_{\text {creat }} \\
\text { tertile }\end{array}$ & 478 & 398 & 297 & 199 & 135 & 40 \\
$\begin{array}{l}\text { Intermediate } \\
\text { U: } P_{\text {creat }} \text { tertile }\end{array}$ & 479 & 429 & 355 & 260 & 186 & 68 \\
$\begin{array}{l}\text { High U: } P_{\text {creat }} \\
\text { tertile }\end{array}$ & 479 & 426 & 312 & 239 & 164 & 55 \\
\hline
\end{tabular}

(c)

FIGURE 1: Cumulative risk of all-cause death according to urinary solute tertiles. (a) Kaplan-Meier survival curves are displayed according to tertiles of urinary sodium concentration $\left(\mathrm{U}_{\mathrm{Na}}\right)$ at baseline. Patient grouping: solid line indicates high $\mathrm{U}_{\mathrm{Na}}$ tertile patients; dashed line indicates intermediate $\mathrm{U}_{\mathrm{Na}}$ tertile patients; dotted line indicates low $\mathrm{U}_{\mathrm{Na}}$ tertile patients. $P$ value Log-rank test $<0.001$. (b) Kaplan-Meier survival curves are displayed according to tertiles of urinary potassium concentrations $\left(\mathrm{U}_{\mathrm{K}}\right)$ at baseline. Patient grouping: solid line indicates high $\mathrm{U}_{\mathrm{K}}$ tertile patients; dashed line indicates intermediate $\mathrm{U}_{\mathrm{K}}$ tertile patients; dotted line indicates low $\mathrm{U}_{\mathrm{K}}$ tertile patients. $P$ value Log-rank test $<0.001$. (c) Kaplan-Meier survival curves are displayed according to tertiles of urine to plasma creatinine concentration ratio $\left(U: P_{\text {creat }}\right)$ at baseline. Patient grouping: solid line indicates high $\mathrm{U}: \mathrm{P}_{\text {creat }}$ tertile patients; dashed line indicates intermediate $\mathrm{U}: \mathrm{P}_{\text {creat }}$ tertile patients; dotted line indicates low $\mathrm{U}: \mathrm{P}_{\text {creat }}$ tertile patients. $P$ value Log-rank test $<0.001$.

had a lower blood pressure at baseline, patients in the low $\mathrm{U}_{\mathrm{Na}}$ tertile had a significantly increased risk of all-cause and cardiovascular deaths. These association appeared to be independent from other known cardiovascular risk factors and also from $U_{K}$, estimated daily sodium intake, index of urine concentration $\left(\mathrm{U}: \mathrm{P}_{\text {creat }}\right)$, and glycosuria. Nevertheless, the extent to which $\mathrm{U}_{\mathrm{Na}}$ improves risk prediction is modest according to the rIDI and the change in $c$-statistics and its value in clinical practice remain to be determined.

Data from prospective epidemiologic studies focusing on estimated or measured $24 \mathrm{~h}$ urinary sodium excretion identified inconsistent association with cardiovascular complications [17-20]. Interestingly estimation of $24 \mathrm{~h}$ urinary sodium excretion in this work presented a magnitude in 

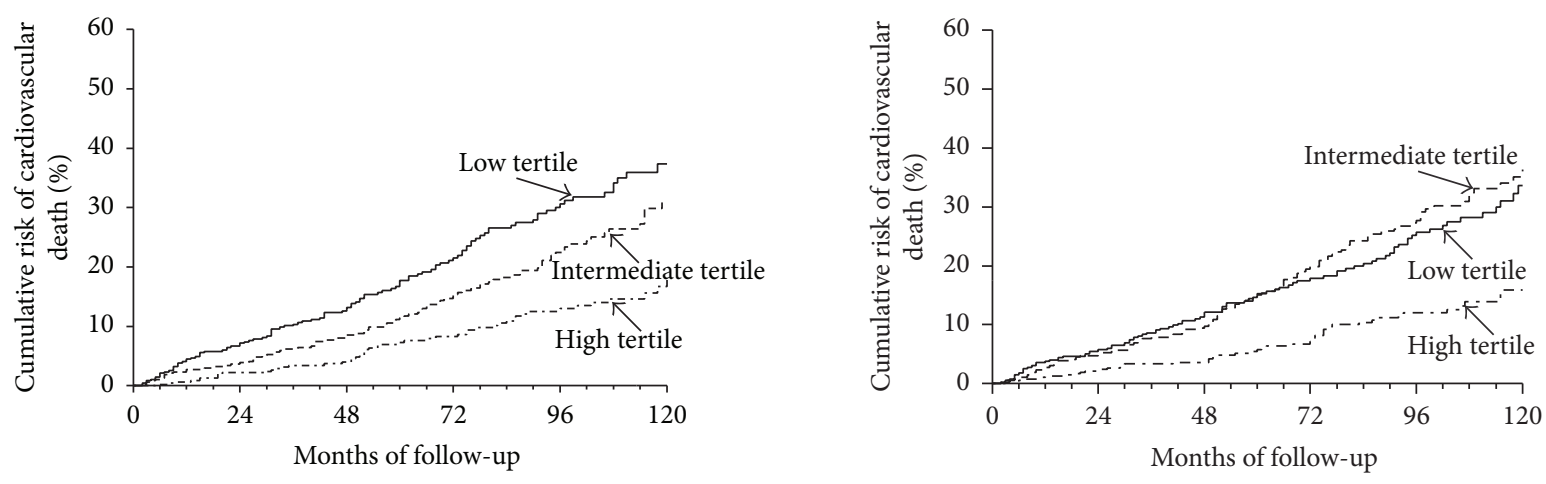

\begin{tabular}{lcccccc}
\hline $\begin{array}{l}\text { Number at } \\
\text { risk }\end{array}$ & & & & & & \\
\hline $\begin{array}{l}\text { Low } \mathrm{U}_{\mathrm{Na}} \\
\text { tertile }\end{array}$ & 479 & 402 & 291 & 196 & 123 & 41 \\
$\begin{array}{l}\text { Intermediate } \\
\mathrm{U}_{\mathrm{Na}} \text { tertile }\end{array}$ & 481 & 426 & 340 & 246 & 169 & 59 \\
$\begin{array}{l}\text { High } \mathrm{U}_{\mathrm{Na}} \\
\text { tertile }\end{array}$ & 479 & 427 & 333 & 256 & 193 & 63 \\
\hline
\end{tabular}

(a)

\begin{tabular}{lcccccc}
\hline $\begin{array}{l}\text { Number at } \\
\text { risk }\end{array}$ & & & & & & \\
\hline $\begin{array}{l}\text { Low } \mathrm{U}_{\mathrm{K}} \\
\text { tertile }\end{array}$ & 485 & 416 & 307 & 210 & 144 & 49 \\
$\begin{array}{l}\text { Intermediate } \\
\mathrm{U}_{\mathrm{K}} \text { tertile }\end{array}$ & 477 & 416 & 326 & 225 & 150 & 54 \\
$\begin{array}{l}\text { High } \mathrm{U}_{\mathrm{K}} \\
\text { tertile }\end{array}$ & 477 & 423 & 331 & 263 & 191 & 60 \\
\hline
\end{tabular}

(b)

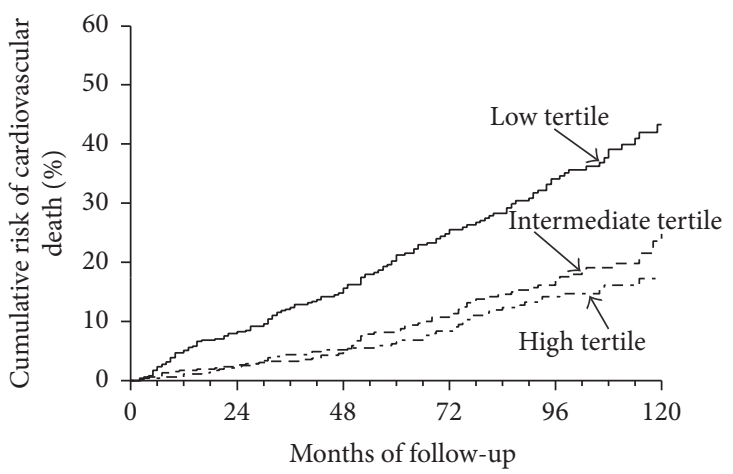

\begin{tabular}{lcccccc}
\hline $\begin{array}{l}\text { Number at } \\
\text { risk }\end{array}$ & & & & & & \\
\hline $\begin{array}{l}\text { Low U }: P_{\text {creat }} \\
\text { tertile }\end{array}$ & 478 & 398 & 297 & 199 & 135 & 40 \\
$\begin{array}{l}\text { Intermediate } \\
\text { U: } P_{\text {creat }} \text { tertile }\end{array}$ & 479 & 429 & 355 & 260 & 186 & 68 \\
$\begin{array}{l}\text { High U: } P_{\text {creat }} \\
\text { tertile }\end{array}$ & 479 & 426 & 312 & 239 & 164 & 55 \\
\hline
\end{tabular}

(c)

FIGURE 2: Cumulative risk of cardiovascular death according to urinary solute tertiles. (a) Kaplan-Meier survival curves are displayed according to tertiles of urinary sodium concentration $\left(\mathrm{U}_{\mathrm{Na}}\right)$ at baseline. Patient grouping: solid line indicates high $\mathrm{U}_{\mathrm{Na}}$ tertile patients; dashed line indicates intermediate $\mathrm{U}_{\mathrm{Na}}$ tertile patients; grey line indicates low $\mathrm{U}_{\mathrm{Na}}$ tertile patients. $P$ value Log-rank test $<0.001$. (b) Kaplan-Meier survival curves are displayed according tertiles of urinary potassium concentrations $\left(\mathrm{U}_{\mathrm{K}}\right)$ at baseline. Patient grouping: solid line indicates high $\mathrm{U}_{\mathrm{K}}$ tertile patients; dashed line indicates intermediate $\mathrm{U}_{\mathrm{K}}$ tertile patients; dotted line indicates low $\mathrm{U}_{\mathrm{K}}$ tertile patients. $P$ value Log-rank test $<0.001$. (c) Kaplan-Meier survival curves are displayed according to tertiles of urine to plasma creatinine concentration ratio (U : $\left.P_{\text {creat }}\right)$ at baseline. Patient grouping: solid line indicates high $\mathrm{U}: \mathrm{P}_{\text {creat }}$ tertile patients; dashed line indicates intermediate $\mathrm{U}: \mathrm{P}_{\text {creat }}$ tertile patients; dotted line indicates low $\mathrm{U}: \mathrm{P}_{\text {creat }}$ tertile patients. $P$ value Log-rank test $<0.001$.

accordance with other reports [21, 22]. However recent T1D and large-scale general population studies have identified a J-shape relationship $[5,23]$. We also reported, in the T2D SURDIAGENE study population, this nonlinear pattern [6]. A recent publication showed that serum sodium concentration was associated with mortality independently of copeptin in a distinct general practitioner-recruited $\mathrm{T} 2 \mathrm{D}$ population [24].
Nevertheless clinical trials have demonstrated that reduced sodium intake lowered blood pressure [25]. However interventions lowering salt intake have not established a definite clinical benefit either in the general or more particularly in the T2D population [26-28]. The low $\mathrm{Na}$ excretion may be due to insulin therapy, which is more frequent in the low tertile of $U_{\mathrm{Na}}$. The antinatriuretic effect of insulin may contribute to the relationship between insulin 
TABLE 2: Association of clinical and biological characteristic variables with measured urinary sodium concentration (Spearman's correlation).

\begin{tabular}{lcc}
\hline & Estimate $(95 \%$ CI $)$ & $P$ value \\
\hline Age & $-0.09(-0.15$ to -0.04$)$ & $<0.001$ \\
Male gender & $-0.16(-0.26$ to -0.05$)$ & 0.004 \\
History of cardiovascular disease & $-0.18(-0.31$ to -0.05$)$ & 0.008 \\
Use of diuretics & $-0.30(-0.41$ to -0.20$)$ & $<0.001$ \\
Use of insulin & $-0.24(-0.34$ to -0.14$)$ & $<0.001$ \\
eGFR & $0.28(0.23$ to 0.33$)$ & $<0.001$ \\
uACR & $-0.14(-0.19$ to -0.09$)$ & $<0.001$ \\
$\mathrm{U}_{\mathrm{K}}$ & $0.18(0.13$ to 0.24$)$ & $<0.001$ \\
U: creat $_{\text {estimated } 24 \text { h Na excretion }}$ & $0.18(0.13$ to 0.23$)$ & $<0.001$ \\
NT-proBNP & $0.29(0.26$ to 0.31$)$ & $<0.001$ \\
Glycosuria & $-0.22(-0.27$ to -0.17$)$ & $<0.001$ \\
\hline
\end{tabular}

Estimates are calculated for 1-SD increment of continuous variables. eGFR, estimated glomerular filtration rate; uACR, urinary albumin/creatinine ratio; $\mathrm{U}_{\mathrm{K}}$, urinary potassium concentration; $\mathrm{U}: \mathrm{P}_{\text {creat }}$, urine to plasma creatinine ratio; NT-proBNP, N-terminal pro-brain natriuretic peptide. uACR, copeptin, and NT-proBNP are log-transformed.

resistance and hypertension [29], and patients in the low $\mathrm{U}_{\mathrm{Na}}$ tertile also require less antihypertensive therapy. The question whether low $\mathrm{U}_{\mathrm{Na}}$ may play a role in higher mortality in insulin-treated patients as recently reported [30] will need more research.

Our key finding is that $\mathrm{U}_{\mathrm{Na}}$ constitutes a prognostic factor for all-cause and cardiovascular mortality in T2D patients. To the best of our knowledge, no similar conclusions had previously been reached. Interestingly, our data support the hypothesis that the kidney capacity to excrete water and solute in the urine is implicated in the occurrence of fatal cardiovascular complications. This hypothesis would benefit from reanalyzing previous studies. However, our current findings propose a shift of paradigm from simple sodium intake to a more complex phenomenon associated with cardiovascular death: the kidney's ability to excrete sodium. As sodium concentration is lower in urine compared to plasma, the kidney independently regulates the amount of water required to excrete solutes. Our data on $\mathrm{U}_{\mathrm{Na}}$ but also on $\mathrm{U}: \mathrm{P}_{\text {creat }}$ support the likelihood that a higher excretion of water leading to a lower $\mathrm{U}_{\mathrm{Na}}$ is particularly ominous. Though urinary osmolarity is lacking, this speculation needs validation.

The pathophysiology underlying such relationships remains unclear. The potentially involved biological systems are those contributing to the regulation of sodium and volemia. The natriuretic peptides and vasopressin, the reninangiotensin-aldosterone system (RAS), or the sympathetic nervous system (SNS) could all play a role.

Low $\mathrm{U}_{\mathrm{Na}}$ was associated with low SBP levels in our population. Because these conditions could be present in CHF, we adjusted our analyses for NT-proBNP, a marker of $\mathrm{CHF}$, and we analyzed separately patients without history of cardiovascular disease. Indeed $\mathrm{Na}$ and water excretion was impaired in CHF [31] whereas NT-proBNP is markedly increased. Nevertheless, adjustment for NT-proBNP did not attenuate the prognostic value of $\mathrm{U}_{\mathrm{Na}}$. We also tried to determine whether low $U_{\mathrm{Na}}$ could be related to arginine vasopressin (AVP), the hormone fine-tuning water excretion in the kidney collecting duct. Because AVP is difficult to measure, measurement of copeptin, the $\mathrm{N}$-terminal part of the AVP prohormone, is now widely used as a proxy of AVP concentration [32]. High copeptin concentration was shown to be an important biomarker for renal and all-cause mortality in 2 independent cohorts of T2D patients [24, 33]. As copeptin is secreted when water reabsorption is required, its concentration was expected to be higher in patients with high $\mathrm{U}_{\mathrm{Na}}$. Indeed the higher $\mathrm{U}_{\mathrm{Na}}$, the higher copeptin concentration. In addition, as glycosuria may contribute to fluid loss in T2D patients, we confirmed that plasma copeptin was higher in patients with glycosuria compared to nonglycosuric patients (data not shown). As the deleterious effect of low $U_{\mathrm{Na}}$ remained significant after adjustment for copeptin concentration, plasma copeptin concentration is unlikely to be the sole contributing factor between $\mathrm{U}_{\mathrm{Na}}$ and cardiovascular death.

We then examined the possible implications of RAS activation. This hormonal pathway was shown to be associated with several cardiovascular and renal outcomes following genetic and pharmacologic approaches [34]. The RAS is activated when sodium intake decreases, as has recently been shown in patients with diabetes [35]. Even if the RAS could be a possible explanation for our findings, two factors speak against a deleterious role of the RAS. First, our observations were barely affected when adjusting for RAS blockade treatment into multivariate models. Second, the activation of the RAS leads to reduced urinary sodium excretion at the expense of increased potassium excretion. As sodium and potassium move in opposite directions when RAS is activated, our finding of an increased risk for cardiovascular death with both low sodium and low potassium suggests that RAS activation is not the main contributor.

A third explanation focused on renal SNS. Diabetes is associated with autonomic dysfunction and sympathetic/parasympathetic imbalance [36]. Overactivity of the renal SNS leads to increase in renin secretion rate, decrease in urinary sodium excretion (by increasing renal tubular sodium reabsorption), and decrease in renal blood flow [37]. In addition, decreased sodium intake leads to an increase in catecholamines [34]. Our observations were barely affected when adjusting for beta blocker treatment into multivariate models. Direct and accurate measurement of the autonomic nervous system was not available at baseline. Even though it has yet to be comprehensively detailed, its role could still help to explain our results. While possible use of low $\mathrm{U}_{\mathrm{Na}}$ as a valuable surrogate for overactivity of renal SNS requires future confirmation, it can be speculated that early detected SNS dysregulation may reveal possible targets for pharmacological intervention (such as beta blockers), but also for nonpharmacological interventions such as renal denervation or barostimulation that are currently under evaluation [38].

Some limitations in our study must be acknowledged. This study was not designed to collect 24-hour urine and exploration of the relation between $\mathrm{U}_{\mathrm{Na}}$ and measured daily 
TABLE 3: Cox proportional hazards models for the risk of all-cause death.

\begin{tabular}{lccc}
\hline & $\begin{array}{c}\text { Univariate } \\
\text { Crude }\end{array}$ & $P$ value & $\begin{array}{c}\text { Model A } \\
\text { Adjusted }\end{array}$ \\
\hline $\mathrm{U}_{\mathrm{Na}}$ & hazard ratio $(95 \% \mathrm{CI})$ & hazard ratio $(95 \% \mathrm{CI})$ & $0.73(0.63$ to 0.85$)$ \\
$\mathrm{U}: \mathrm{P}_{\text {creat }}$ & $0.71(0.64$ to 0.79$)$ & $<0.001$ & $0.99(0.84$ to 1.16$)$ \\
\hline
\end{tabular}

Hazard ratios were standardized by calculating them for 1-SD increment of each continuous variable.

Model $A=U_{\mathrm{Na}}, \mathrm{U}_{\mathrm{K}}, \mathrm{U}: \mathrm{P}_{\text {creat }}$, age, sex and estimated $24 \mathrm{~h}-\mathrm{Na}$ excretion.

TABLE 4: Multivariate Cox proportional hazards model for the risk of all-cause death (best fitted model).

\begin{tabular}{lcc}
\hline & $\begin{array}{c}\text { Adjusted } \\
\text { hazard ratio }(95 \%\end{array}$ & $P$ value \\
\hline Age & $1.78(1.58$ to 2.01$)$ & $<0.001$ \\
Sex: (reference = men) & $0.68(0.55$ to 0.84$)$ & $<0.001$ \\
Use of Insulin & $1.51(1.21$ to 1.89$)$ & $<0.001$ \\
eGFR & $1.16(1.02$ to 1.32$)$ & 0.03 \\
uACR & $1.30(1.17$ to 1.44$)$ & $<0.001$ \\
U $_{\text {Na }}$ & $0.79(0.71$ to 0.88$)$ & $<0.001$ \\
Copeptin & $1.19(1.06$ to 1.33$)$ & 0.004 \\
NT-proBNP & $1.56(1.38$ to 1.75$)$ & $<0.001$ \\
\hline
\end{tabular}

Hazard ratios were standardized by calculating them for 1-SD increment of each continuous variable.

eGFR, estimated glomerular filtration rate; uACR, urinary albumin to creatinine concentration ratio; $\mathrm{U}_{\mathrm{Na}}$, urinary sodium concentration; NTproBNP, N-terminal pro-brain natriuretic peptide.

uACR, copeptin, and NT-proBNP are log-transformed.

urinary sodium excretion in our cohort was therefore beyond our scope. We based our analysis on a single voided morning urine sample, which represents usual individual solute [39]. Misclassification of patients due to fluctuations of solute excretion should rather lead to false negative, rather than false positive findings.

While urinary sodium excretion rate is known to exhibit a daily (circadian) to weekly (circaseptan) pattern [40, 41], in the present study, one-time spot urinary samples were drawn at close times for all patients. However 24-hour urine samples cannot evidence impaired circadian pattern of water and $\mathrm{Na}$ excretion rates in diabetes, if any, as shown in the metabolic syndrome [42].

We performed no dietary assessment of salt or fluid intake, and information regarding timed urine volume was not available. Although 24-hour urine samples are theoretically more satisfactory as a surrogate for daily sodium excretion [12], they present some pitfalls in this type of study. The collection of urine may not be complete, and incompleteness may be systematically biased, in which case, statistical association may be misleading. Our study is based on a single morning urine sample, similar to what has been considered in other recent studies [43]. Even if multiple-time spots mean $\mathrm{U}_{\mathrm{Na}}$ may provide less intrasubject variability compared to one-time spot $\mathrm{U}_{\mathrm{Na}}$, it is unlikely to affect intersubject variability. In addition, this approach of repeated urinary sampling seems not feasible for large epidemiologic studies. However, our study also has a number of strengths. The size of our cohort allows detection of low level associations. An independent adjudication committee validated all single events. Three independently measured urinary variables $\left(\mathrm{U}_{\mathrm{Na}}, \mathrm{U}_{\mathrm{K}}\right.$, and $\left.\mathrm{U}: \mathrm{P}_{\text {creat }}\right)$ provided similar trends.

\section{Conclusions}

In conclusion, we have evidenced that $\mathrm{U}_{\mathrm{Na}}$ measured in the morning can be proposed as new a biomarker of risk of allcause and cardiovascular mortality, in type 2 diabetes patient.

\section{Competing Interests}

No competing interests were known or perceived.

\section{Acknowledgments}

The authors wish to thank Elodie Rogeon (Inserm CIC1402, Poitiers, France) for administrative help. The staff of the Poitiers University Hospital Diabetes Department is acknowledged for data collection and monitoring help. The authors thank Sonia Brishoual (Biological Resources Center, BRC BB-0033-00068, Poitiers, France) for biological determinations and Alexandre Pavy and Marie-Claire Pasquier (Information Technology Department, CHU de Poitiers, Poitiers, France). They also thank Dr. W.C. Knowler (NIDDK, Phoenix, AZ) for his critical comments and discussions. They are also grateful to Jeffrey Arsham for editing the English of the manuscript. The independent adjudication committee of the SURDIAGENE study included the following persons: Jean Michel Halimi (Chairman Tours, France), Gregory Ducrocq (Paris, France), Ronan Roussel (Paris, France), Pierre Llaty (Poitiers, France), Vincent Rigalleau (Bordeaux, France), Charlotte Hulin (Poitiers, France), David Montaigne (Lille, France), and Philippe Zaoui (Grenoble, France). The members of SURDIAGENE study group included Samy Hadjadj, M.D., Ph.D., CHU de Poitiers; Richard Marechaud M.D., CHU de Poitiers; Stéphanie Ragot, Pharm.D. Ph.D., CHU de Poitiers; Xavier Piguel, M.D., CHU Poitiers; PierreJean Saulnier, M.D., Ph.D., CHU de Poitiers; Vincent Javaugue, M.D., CHU Poitiers; Elise Gand, M.S., CHU Poitiers; Charlotte Hulin-Delmotte, M.D.; Pierre Llatty, M.D.; Gregory Ducrocq, M.D., Ph.D., Assistance Public-Hôpitaux de Paris; 
TABLE 5: Cox proportional hazards models for the risk of cardiovascular death.

\begin{tabular}{lccc}
\hline & $\begin{array}{c}\text { Univariate } \\
\text { Crude }\end{array}$ & $P$ value & $\begin{array}{c}\text { Model A } \\
\text { Adjusted }\end{array}$ \\
\hline $\mathrm{U}_{\mathrm{Na}}$ & hazard ratio $(95 \% \mathrm{CI})$ & hazard ratio $(95 \% \mathrm{CI})$ & $0.66(0.54$ to 0.81$)$ \\
$\mathrm{U}: \mathrm{P}_{\text {creat }}$ & $0.65(0.56$ to 0.74$)$ & $<0.001$ & $0.89(0.74$ to 1.07$)$ \\
\hline
\end{tabular}

Hazard ratios were standardized by calculating them for 1-SD increment of each continuous variable.

Model $A=U_{\mathrm{Na}}, \mathrm{U}_{\mathrm{K}}, \mathrm{U}: \mathrm{P}_{\text {creat }}$, age, sex and estimated $24 \mathrm{~h}-\mathrm{Na}$ excretion.

TABLE 6: Risk of cardiovascular death according to Cox model [left] and Fine and Gray competing risk [right] model.

\begin{tabular}{|c|c|c|c|c|}
\hline & $\begin{array}{c}\text { Adjusted } \\
\text { hazard ratio } \\
(95 \% \mathrm{CI})\end{array}$ & $P$ value & $\begin{array}{c}\text { Adjusted } \\
\text { subhazard ratio* } \\
(95 \% \mathrm{CI})\end{array}$ & $P$ value \\
\hline Age & 1.76 (1.50 to 2.07$)$ & $<0.001$ & 1.53 (1.30 to 1.79$)$ & $<0.001$ \\
\hline Sex: (reference men) & $0.66(0.50$ to 0.86$)$ & 0.002 & 0.73 (0.56 to 0.95$)$ & 0.02 \\
\hline BMI & $1.19(1.04$ to 1.36$)$ & 0.01 & $1.13(0.99$ to 1.28$)$ & 0.07 \\
\hline Use of Insulin & $1.62(1.20$ to 2.19$)$ & 0.002 & $1.57(1.15$ to 2.14$)$ & 0.005 \\
\hline uACR & 1.26 (1.11 to 1.42$)$ & $<0.001$ & $1.19(1.04$ to 1.36$)$ & 0.01 \\
\hline $\mathrm{U}_{\mathrm{Na}}$ & $0.76(0.66$ to 0.88$)$ & $<0.001$ & $0.82(0.71$ to 0.95$)$ & 0.007 \\
\hline NT-proBNP & $1.90(1.66$ to 2.18$)$ & $<0.001$ & $1.80(1.56$ to 2.08$)$ & $<0.001$ \\
\hline
\end{tabular}

Hazard ratios were standardized by calculating them for 1-SD increment of each continuous variable. History of uACR, urinary albumin to creatinine concentration ratio; $\mathrm{U}_{\mathrm{Na}}$, urinary sodium concentration; NT-proBNP, N-terminal pro-brain natriuretic peptide.

uACR and NT-proBNP are log-transformed.

${ }^{*}$ Cox proportional subhazards ratios for the risk of cardiovascular death are computed according to Fine and Gray competing risk models when taking into account the competing risk of noncardiovascular death.

Ronan Roussel, M.D., Ph.D., Assistance Public-Hôpitaux de Paris, M.D., Ph.D.; Vincent Rigalleau, M.D., Ph.D., CHU Bordeaux; Yann Pucheu, M.D., CHU Bordeaux; Philippe Zaoui, M.D., Ph.D., CHU Grenoble; David Montaigne, M.D., Ph.D., CHU Lille; Jean-Michel Halimi, M.D., Ph.D., CHU Tours; Phillipe Gatault, M.D., Ph.D., CHU Tours; Philippe Sosner, M.D., Ph.D., Laboratoire MOVE EA6314; Barnabas Gellen, M.D., Ph.D., Polyclinique de Poitiers.

\section{References}

[1] S. R. K. Seshasai, S. Kaptoge, A. Thompson et al., "Diabetes mellitus, fasting glucose, and risk of cause-specific death," New England Journal of Medicine, vol. 364, no. 9, pp. 829-841, 2011.

[2] R. Lozano, M. Naghavi, K. Foreman et al., "Global and regional mortality from 235 causes of death for 20 age groups in 1990 and 2010: a systematic analysis for the Global Burden of Disease Study 2010," The Lancet, vol. 380, no. 9859, pp. 2095-2128, 2012.

[3] A. Mente, M. J. O’Donnell, S. Rangarajan et al., "Association of urinary sodium and potassium excretion with blood pressure," The New England Journal of Medicine, vol. 371, no. 7, pp. 601-611, 2014.

[4] A. Smyth, M. O'Donnell, A. Mente, and S. Yusuf, "Dietary sodium and cardiovascular disease," Current Hypertension Reports, vol. 17, no. 6, article 559, 2015.

[5] M. C. Thomas, J. Moran, C. Forsblom et al., "The association between dietary sodium intake, ESRD, and all-cause mortality in patients with type 1 diabetes," Diabetes Care, vol. 34, no. 4, pp. 861-866, 2011.

[6] P. J. Saulnier, E. Gand, S. Hadjadj, and S. S. Group, "Sodium and cardiovascular disease," New England Journal of Medicine, vol. 371, no. 22, pp. 2134-2139, 2014.
[7] E. I. Ekinci, J. L. Moran, M. C. Thomas et al., "Relationship between urinary sodium excretion over time and mortality in type 2 diabetes," Diabetes Care, vol. 37, no. 4, pp. e62-e63, 2014.

[8] S. Hadjadj, F. Fumeron, R. Roussel et al., "Prognostic value of the insertion/deletion polymorphism of the ACE gene in type 2 diabetic subjects: results from the Non-Insulin-Dependent Diabetes, Hypertension, Microalbuminuria or Proteinuria, Cardiovascular Events, and Ramipril (DIABHYCAR), Diabete de type 2, Nephropathie et Genetique (DIAB2NEPHROGENE), and Survie, Diabete de type 2 et Genetique (SURDIAGENE) studies," Diabetes Care, vol. 31, no. 9, pp. 1847-1852, 2008.

[9] A. S. Levey, L. A. Stevens, C. H. Schmid et al., "A new equation to estimate glomerular filtration rate," Annals of Internal Medicine, vol. 150, no. 9, pp. 604-612, 2009.

[10] T. Kawasaki, K. Itoh, K. Uezono, and H. Sasaki, "A simple method for estimating $24 \mathrm{~h}$ urinary sodium and potassium excretion from second morning voiding urine specimen in adults," Clinical and Experimental Pharmacology \& Physiology, vol. 20, no. 1, pp. 7-14, 1993.

[11] T. Tanaka, T. Okamura, K. Miura et al., "A simple method to estimate populational 24 -h urinary sodium and potassium excretion using a casual urine specimen," Journal of Human Hypertension, vol. 16, no. 2, pp. 97-103, 2002.

[12] L. Huang, M. Crino, J. H. Y. Wu et al., "Mean population salt intake estimated from 24-h urine samples and spot urine samples: a systematic review and meta-analysis," International Journal of Epidemiology, vol. 45, no. 1, pp. 239-250, 2016.

[13] L. Bankir, J. Perucca, and M. H. Weinberger, "Ethnic differences in urine concentration: possible relationship to blood pressure," Clinical Journal of the American Society of Nephrology, vol. 2, no. 2, pp. 304-312, 2007. 
[14] M. J. Penciana and R. B. D’Agostino, “Overall C as a measure of discrimination in survival analysis: model specific population value and confidence interval estimation," Statistics in Medicine, vol. 23, no. 13, pp. 2109-2123, 2004.

[15] M. J. Pencina, S. D’Agostino, J. D’Agostino, and R. S. Vasan, "Evaluating the added predictive ability of a new marker: from area under the ROC curve to reclassification and beyond," Statistics in Medicine, vol. 27, no. 2, pp. 157-172, 2008.

[16] J. P. Fine and R. J. Gray, "A proportional hazards model for the subdistribution of a competing risk," Journal of the American Statistical Association, vol. 94, no. 446, pp. 496-509, 1999.

[17] E. I. Ekinci, S. Clarke, M. C. Thomas et al., "Dietary salt intake and mortality in patients with type 2 diabetes," Diabetes Care, vol. 34, no. 3, pp. 703-709, 2011.

[18] K. Stolarz-Skrzypek, T. Kuznetsova, L. Thijs et al., "Fatal and nonfatal outcomes, incidence of hypertension, and blood pressure changes in relation to urinary sodium excretion," JAMA Journal of the American Medical Association, vol. 305, no. 17, pp. 1777-1785, 2011.

[19] Q. Yang, T. Liu, E. V. Kuklina et al., "Sodium and potassium intake and mortality among US adults: prospective data from the third national health and nutrition examination survey," Archives of Internal Medicine, vol. 171, no. 13, pp. 1183-1191, 2011.

[20] J. Tuomilehto, P. Jousilahti, D. Rastenyte et al., "Urinary sodium excretion and cardiovascular mortality in Finland: a prospective study," The Lancet, vol. 357, no. 9259, pp. 848-851, 2001.

[21] D. A. Mccarron, A. G. Kazaks, J. C. Geerling, J. S. Stern, and N. A. Graudal, "Normal range of human dietary sodium intake: a perspective based on 24-hour urinary sodium excretion worldwide," American Journal of Hypertension, vol. 26, no. 10, pp. 1218-1223, 2013.

[22] D. Mozaffarian, S. Fahimi, G. M. Singh et al., "Global sodium consumption and death from cardiovascular causes," New England Journal of Medicine, vol. 371, no. 7, pp. 624-634, 2014.

[23] M. O’Donnell, A. Mente, S. Rangarajan et al., "Urinary sodium and potassium excretion, mortality, and cardiovascular events," The New England Journal of Medicine, vol. 371, no. 7, pp. 612-623, 2014.

[24] I. J. Riphagen, W. E. Boertien, A. Alkhalaf et al., "Copeptin, a surrogate marker for arginine vasopressin, is associated with cardiovascular and all-cause mortality in patients with type 2 diabetes (ZODIAC-31)," Diabetes Care, vol. 36, no. 10, pp. 3201$3207,2013$.

[25] F. J. He, J. Li, and G. A. MacGregor, "Effect of longer term modest salt reduction on blood pressure: cochrane systematic review and meta-analysis of randomised trials," BMJ (Online), vol. 346, no. 7903, Article ID f1325, 2013.

[26] M. Bochud, P. Marques-Vidal, M. Burnier, and F. Paccaud, "Dietary salt intake and cardiovascular disease: summarizing the evidence," Public Health Reviews, vol. 33, pp. 530-552, 2012.

[27] F. J. He and G. A. MacGregor, "Salt reduction lowers cardiovascular risk: meta-analysis of outcome trials," The Lancet, vol. 378, no. 9789, pp. 380-382, 2011.

[28] M. J. O’Donnell, A. Mente, A. Smyth, and S. Yusuf, "Salt intake and cardiovascular disease: why are the data inconsistent?" European Heart Journal, vol. 34, no. 14, pp. 1034-1040, 2013.

[29] R. O. B. Gans, H. J. G. Bilo, and A. J. M. Donker, "The renal response to exogenous insulin in non-insulin-dependent diabetes mellitus in relation to blood pressure and cardiovascular hormonal status," Nephrology Dialysis Transplantation, vol. 11, no. 5, pp. 794-802, 1996.

[30] C. L. Roumie, R. A. Greevy, C. G. Grijalva et al., "Association between intensification of metformin treatment with insulin vs sulfonylureas and cardiovascular events and all-cause mortality among patients with diabetes," JAMA - Journal of the American Medical Association, vol. 311, no. 22, pp. 2288-2296, 2014.

[31] P. R. Kalra, S. D. Anker, and A. J. S. Coats, "Water and sodium regulation in chronic heart failure: the role of natriuretic peptides and vasopressin," Cardiovascular Research, vol. 51, no. 3, pp. 495-509, 2001.

[32] S. Balanescu, P. Kopp, M. B. Gaskill, N. G. Morgenthaler, C. Schindler, and J. Rutishauser, "Correlation of plasma copeptin and vasopressin concentrations in hypo-, iso-, and hyperosmolar states," Journal of Clinical Endocrinology and Metabolism, vol. 96, no. 4, pp. 1046-1052, 2011.

[33] G. Velho, N. Bouby, S. Hadjadj et al., "Plasma copeptin and renal outcomes in patients with type 2 diabetes and albuminuria," Diabetes Care, vol. 36, no. 11, pp. 3639-3645, 2013.

[34] N. A. Graudal, T. Hubeck-Graudal, and G. Jürgens, "Effects of low-sodium diet vs. high-sodium diet on blood pressure, renin, aldosterone, catecholamines, cholesterol, and triglyceride (Cochrane Review)," American Journal of Hypertension, vol. 25, no. 1, pp. 1-15, 2012.

[35] R. Libianto, G. Jerums, Q. Lam et al., "Relationship between urinary sodium excretion and serum aldosterone in patients with diabetes in the presence and absence of modifiers of the renin-angiotensin-aldosterone system," Clinical Science, vol. 126, no. 2, pp. 147-154, 2014.

[36] A. I. Vinik, R. E. Maser, B. D. Mitchell, and R. Freeman, “Diabetic autonomic neuropathy," Diabetes Care, vol. 26, no. 5, pp. 1553-1579, 2003.

[37] G. F. DiBona and M. Esler, "Translational medicine: the antihypertensive effect of renal denervation," American Journal of Physiology, vol. 298, no. 2, pp. R245-R253, 2010.

[38] H. Krum, M. P. Schlaich, P. A. Sobotka et al., "Percutaneous renal denervation in patients with treatment-resistant hypertension: final 3-year report of the Symplicity HTN-1 study," The Lancet, vol. 383, no. 9917, pp. 622-629, 2014.

[39] M. Kawamura, A. Ohmoto, T. Hashimoto, F. Yagami, M. Owada, and T. Sugawara, "Second morning urine method is superior to the casual urine method for estimating daily salt intake in patients with hypertension," Hypertension Research, vol. 35, no. 6, pp. 611-616, 2012.

[40] D. Firsov and O. Bonny, "Circadian regulation of renal function," Kidney International, vol. 78, no. 7, pp. 640-645, 2010.

[41] N. Rakova, K. Jüttner, A. Dahlmann et al., "Long-term space flight simulation reveals infradian rhythmicity in human $\mathrm{Na}(+)$ balance," Cell Metabolism, vol. 17, no. 1, pp. 125-131, 2013.

[42] H. Uno, L. Tian, T. Cai, I. S. Kohane, and L. J. Wei, "A unified inference procedure for a class of measures to assess improvement in risk prediction systems with survival data," Statistics in Medicine, vol. 32, no. 14, pp. 2430-2442, 2013.

[43] P. M. Lamelas, A. Mente, R. Diaz et al., "Association of urinary sodium excretion with blood pressure and cardiovascular clinical events in 17,033 Latin Americans," American Journal of Hypertension, vol. 29, no. 7, pp. 796-805, 2016. 


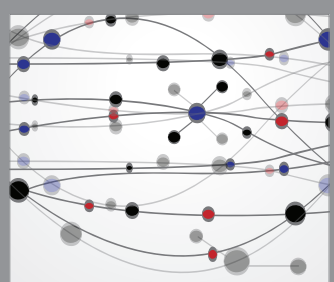

The Scientific World Journal
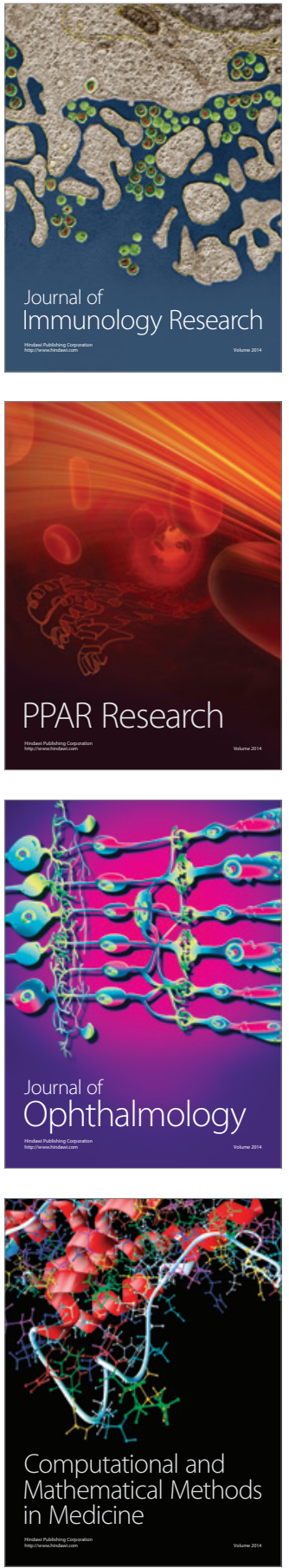

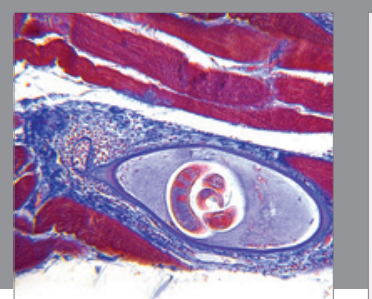

Gastroenterology Research and Practice
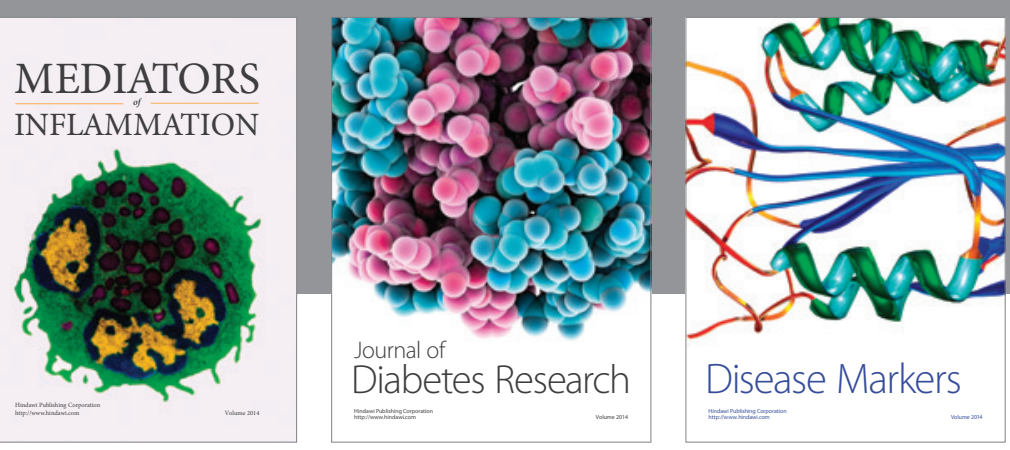

Disease Markers

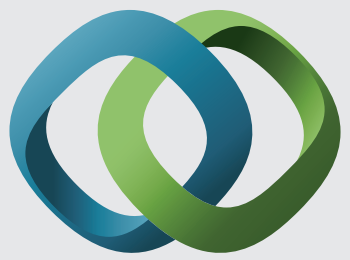

\section{Hindawi}

Submit your manuscripts at

https://www.hindawi.com
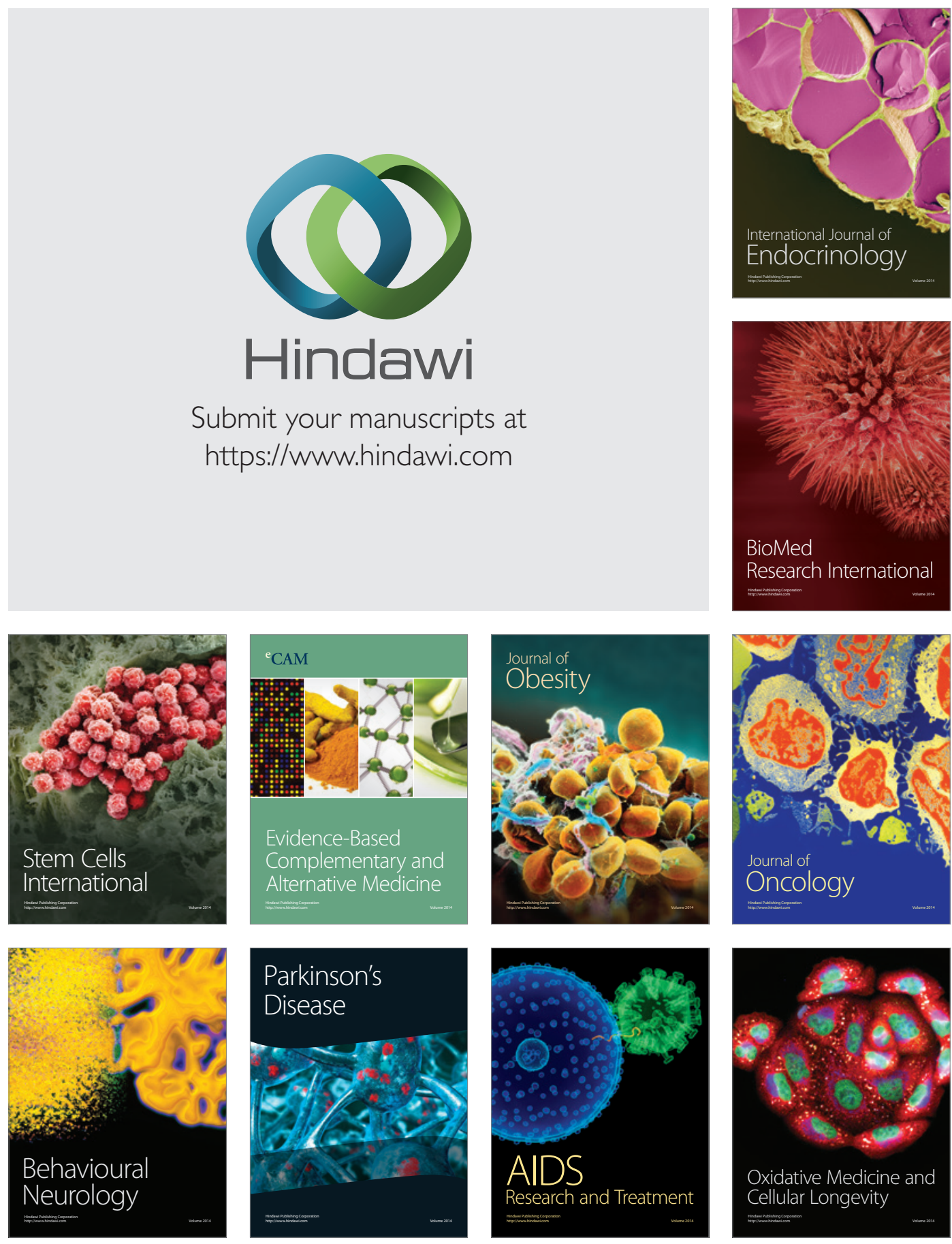